\title{
Atividade Portuária, Globalização e Crescimento de Rio Grande e São José do Norte - RS - Brasil (1990 - 2010)
}

\author{
Port Activity, Globalization and Growth of Rio Grande and São José do Norte - RS - \\ Brazil (1990 - 2010)
}

\author{
Actividad Portuaria, Globalización y Crecimiento de Rio Grande y San José del \\ Norte - RS - Brasil (1990 - 2010)
}

\author{
Claure Morrone Parfitt ${ }^{1}$ \\ Betty Braga Gallo² \\ José Maria Filippini Alba ${ }^{3}$
}

\begin{abstract}
RESUMO: No século XXI a globalização tem impactado as relações porto-cidade no que se refere à sua dinâmica de crescimento, fato observado sobretudo em muitos centros urbanos ao redor do mundo. Observam-se novas formas de articulação da economia brasileira com o capitalismo internacional e também distintas caracterizações das cidades médias do país. Este trabalho tem por objetivo investigar o crescimento econômico, quanto ao PIB (Produto Interno Bruto), populacional e espacial a partir da expansão urbana de Rio Grande e São José do Norte no período de 1990-2010. Foram utilizadas imagens LANDSAT 5 do Sensor Thematic Mapper (TM). Os dados foram processados nos softwares Spring e ArcGIS. Como procedimentos também foi realizada pesquisa bibliográfica, no IBGE, FEE/RS (Fundação de Economia e Estatística do Rio Grande do Sul), entrevistas e visita aos locais de expansão. Os resultados demonstram, neste período, a associação entre o fenômeno da urbanização e a atividade portuária, com o crescimento de ambas as cidades. Conclui-se que proporcionalmente São José do Norte expandiu-se mais do que Rio Grande e ressalta-se o papel do Estado nesse processo.
\end{abstract}

PALAVRAS-CHAVE: Porto. Globalização. Crescimento. Rio Grande. São José do Norte.

ABSTRACT: In the 21st century, globalization has impacted the port-city relations, particularly when it comes to their dynamics of growth. This impact has been observed in many urban centers across the world. Brazil's economy has found new ways to connect with international capitalism, and there have

\footnotetext{
${ }^{1}$ Universidade Federal de Pelotas. End.: Rua Andrade Neves, 1529 - Pelotas, Rio Grande do Sul - Brasil - CEP 96020-080 - e- mail: claurem.parfitt@gmail.com.

2 Universidade Federal de Pelotas. End.: Rua Andrade Neves, 1529 - Pelotas, Rio Grande do Sul - Brasil - CEP 96020-080 - e- mail: bettybraga@yahoo.com.br.

${ }^{3}$ Centro de Pesquisas de Clima Temperado - EMBRAPA - CPACT - Pelotas, Brasil - End. Rodovia BR-392, Km 78, 9o Distrito, Monte Bonito Caixa Postal 403, CEP: 96010-971 - Pelotas, Rio Grande do Sul - e- mail: jose.filippini@gmail.com.
} 
been different characterizations for the mid-sized cities of the country. The present study sought to investigate the economic,(Gross Domestic Product GDP); populational and spatial growth of the cities of Rio Grande and São José do Norte between 1990 and 2010. The study used LANDSAT 5 images from Thematic Mapper (TM) Sensor. The data were processed with Spring and ArcGIS software tools. The procedures also included a bibliographic survey at IBGE and FEE/RS (Economy and Statistics Foundation of the state of Rio Grande do Sul), interviews, as well as visits to the expanding areas. We have concluded that São José do Norte has grown more, proportionally, than Rio Grande, and the Brazilian state had an active role in this process.

KEYWORDS: Port. Globalization. Growth. Rio Grande. São José do Norte.

RESUMEN: En el siglo XXI la globalización ha impactado las relaciones porto-ciudad en lo que se refiere a su dinámica de crecimiento, hecho observado sobre todo en muchos centros urbanos alrededor del mundo. Se observan nuevas formas de articulación de la economía brasileña con el capitalismo internacional y también, distintas caracterizaciones de las ciudades medias del país. Este trabajo tiene por objetivo investigar el crecimiento económico, en cuanto al (PIB) Producto Interno Bruto; la población; y espacial; a partir de la expansión urbana de Rio Grande y San José del Norte en el período 1990-2010. Se utilizaron imágenes LANDSAT 5 del sensor Thematic Mapper (TM). Los datos se procesaron en el software Spring y ArcGIS. Como procedimientos también se realizaron investigaciones bibliográficas, en el IBGE, FEE / RS (Fundación de Economía y Estadística de Rio Grande do Sul) entrevistas y visita a los locales de expansión. Los resultados demuestran en este período, la asociación entre el fenómeno de la urbanización y actividad portuaria con el crecimiento de ambas ciudades. Se concluye que proporcionalmente San José del Norte se expandió más que Rio Grande y se resalta el papel del Estado en ese proceso.

PALABRAS-CLAVE: Puerto. Globalización. Crecimiento. Rio Grande. San José del Norte.

\section{INTRODUÇÃO}

A aceleração de fluxos consiste em uma das características do período histórico geográfico que atualmente vivenciamos. Desde os anos 1990 identificam-se processos de restruturações e desregulamentações, relacionados a territórios, principalmente nas cidades como produto da sociedade urbano-industrial (MARTINS, 2010).

Observam-se no Brasil políticas e períodos de aceleração e desaceleração dos investimentos e consequentemente impactos econômicos na população e estruturas espaciais urbanas.

Com a globalização, novas demandas foram colocadas sobre os portos, o que resultou em mudanças no sistema portuário mundial e nas cidades com portos. Em relação ao porto, destaca-se que o mesmo não pode ser pensado apenas do ponto de vista técnico e operacional. Ele não é apenas um corredor, ele é mais: corresponde a um instrumento a serviço de um projeto de desenvolvimento (GUSMÃO, 2010; MONIÉ, 2011; MONIÉ; VASCONCELOS, 2012). 
O Porto do Rio Grande é uma atividade que pertence ao circuito superior. Trata-se de um polo concentrador de trabalho e de atividades econômicas desempenhando uma função dominante e, embora realize a maior parte de suas atividades localmente, estas "[...] vão integrar-se numa outra cidade de nível superior, no país ou no exterior." (SANTOS, 2008, p. 48). A área de influência do circuito superior não é contínua, porém suas ações repercutem localmente afetando as populações que estão inseridas no circuito inferior.

Localizadas na zona sul do estado do Rio Grande do Sul e pertencentes à Aglomeração Urbana do Sul, Rio Grande e São José do Norte apresentam economia diversificada. Rio Grande consiste em uma cidade média (núcleo), a mais antiga do estado e São Jose do Norte cidade (satélite) a ela imediatamente subordinada.

Rio Grande passou décadas estagnadas economicamente, sem projeções de prosperidade e sem perspectiva de alteração no seu cenário econômico, ambiental e social (DOMINGUES, 2009). No entanto, a partir de 1990, com o incremento da movimentação de cargas, e em 2006, com a decisão do governo federal de reativar a indústria naval brasileira, a cidade começa a ser dinamizada novamente, iniciando seu próximo ciclo econômico com a formação de um Polo Naval, fato que contribuiu para reorganização do território a nível regional, mas principalmente a nível local tendo como foco Rio Grande e São José do Norte.

A globalização, que se manifesta de diferentes modos em razão de suas demandas e de suas contradições, e por intermédio de diversos agentes, e não exclusivamente das grandes corporações, cria e reestrutura novos núcleos urbanos existentes em áreas que passam a integrar o espaço globalizado (CORRÊA, 1999).

Nesse contexto, alguns autores já produziram sobre o crescimento de Rio Grande e São Jose do Norte. Sobre expansão e produção do espaço, Salvatori et al. (1989) e Martins (2006); sobre a questão econômico geográfica, Domingues (2009) e Domingues; Carvalho e Carvalho (2013) e a populacional Feijó e Madono (2013). Já sobre o crescimento de São Jose do Norte tem-se Marques, Siedenberg e Santos (2009). No entanto, quanto à questão do crescimento nos termos de interação Rio Grande - São Jose do Norte nada foi abordado.

Este trabalho parte da hipótese de que o motor do crescimento econômico, demográfico e expansão territorial do tecido urbano das cidades de Rio Grande e São José do Norte de 1990 a 2010 foi basicamente a atividade portuária e a criação do polo naval. Tem por objetivo investigar o crescimento das cidades em questão nas variáveis Produto Interno Bruto, população e expansão da área urbanizada, no período de 1990 a 2010. Sua justificativa respalda-se no interesse em poder vir a subsidiar o planejamento e a gestão dessas cidades. 


\section{CARACTERIZAÇÃO DO UNIVERSO DE ANÁLISE}

\section{A cidade do Rio Grande}

O assentamento da cidade do Rio Grande (figura 1) surgiu com a construção do forte Jesus Maria Jose em 1737. Sua instalação, situada entre Laguna e Buenos Aires, teve um importante papel estratégico somado à sua condição de porto natural na defesa e manutenção do território pelos portugueses. Este forte gerou a seu redor uma pequena povoação que deu origem à cidade. O primeiro registro em forma de planta data de 1767 (SALVATORI et al., 1989).

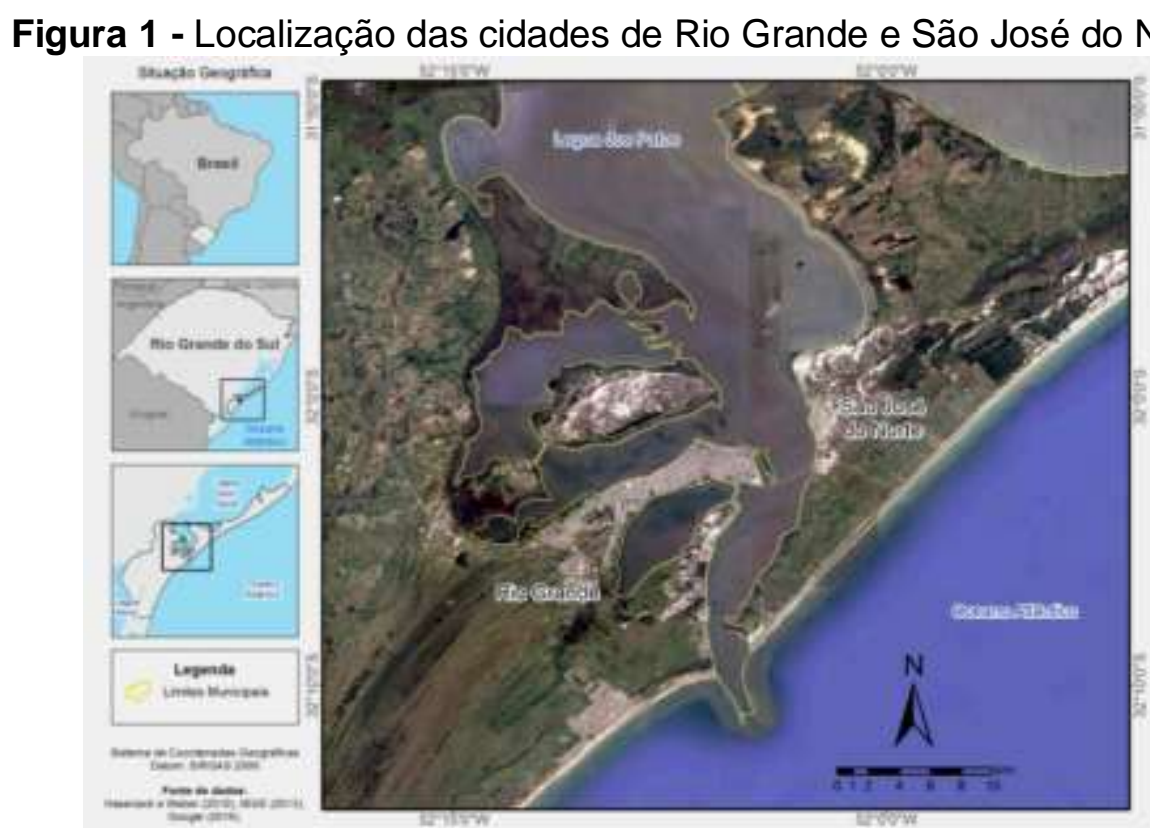

Elaboração: autores (2018).

O assentamento urbano nessa época assume a forma linear acompanhando a margem norte da península, e o forte ocupou uma posição privilegiada em relação à desembocadura da lagoa dos Patos (SALVATORI et al., 1989; WEIMER, 2004).

No século XX, segundo Domingues; Carvalho e Carvalho (2013), a cidade passou por diferentes fases em seu processo de desenvolvimento econômico, e o porto do Rio Grande foi de fundamental importância na definição da economia local e regional. Nos anos 1970 houve a implantação do superporto, do distrito industrial e da infraestrutura de suporte.

A chegada do Polo Naval na cidade de Rio Grande em 2007 foi a maior transformação regional no estado do Rio Grande do Sul desde a década de 1970 (SOUZA, 2014). A instalação de um empreendimento como esse incitou a modificação da matriz produtiva do Estado e oportunizou a dinamização de uma cidade que há décadas estava depreciada economicamente. 
Atualmente Rio Grande é uma cidade de porte médio com 189.472 habitantes (IBGE, 2014) e conta com uma economia diversificada possuindo um distrito industrial composto por empresas que atuam no setor agrícola, alimentício, madeireiro, de energia, químico e metalúrgico e com a possibilidade de instalações na área de energia eólica e de gás natural liquefeito. Sua principal função é a portuária. Apresenta também rica arquitetura em seu centro histórico e o balneário Cassino, o maior do sul do estado.

\section{A cidade de São José do Norte}

A cidade de São Jose do Norte (figura 1) surgiu de uma instalação militar portuguesa. Em 1725 João de Magalhaes é encarregado de construir uma atalaia à margem norte do Canal do Rio Grande, para dar dali apoio aos que traziam gado do sul (IBGE, 2018).

No início da colonização fazia parte de um conjunto de medidas da estratégia de ocupação do acesso à região via lacustre. A localização que deu origem ao povoado não levou em conta a natureza inóspita. O local é extremamente ventoso e cheio de dunas por todos os lados (OLIVEIRA, 2012). De acordo com o autor, a ocupação urbana do centro histórico talvez tenha começado paralelamente ao canal do Rio Grande. Em 1822 a capela da povoação foi elevada à condição de freguesia e em 25 de outubro de 1831 o povoado recebeu a condição de vila, tendo, em 15 de agosto de 1832, obtido a qualificação de município, emancipando-se de Rio Grande (IBGE, 2018).

No momento atual São José do Norte é uma pequena cidade (CORRÊA, 2011) com 17.403 habitantes, localizada às margens do canal que liga a Laguna dos Patos ao oceano Atlântico, situada a três quilômetros de Rio Grande por via fluvial. A economia do município tem como pilares principais a agricultura, o extrativismo vegetal, a pesca e a pecuária.

Com investimento de cerca de $\mathrm{R} \$ 420$ milhões para construção de plataforma de extração de petróleo bruto, o grupo Estaleiros do Brasil (EBR) teve como proposta localizarse cerca de cinco quilômetros da cidade, na estrada da barra (MARQUES; SIEDENBERG; SANTOS, 2009). Com esta implantação a economia municipal deveria passar por grandes mudanças e ter como principal fonte de emprego o polo naval. Assim, toda a economia seria alavancada, transformando a cidade em parte do grande polo naval do sul do estado. Com a situação econômica por que passa o país os investimentos a partir do estaleiro foram comprometidos. 
Atividade Portuária, Globalização e Crescimento de Rio Grande e São José do Norte - RS - Brasil...

\section{PROCEDIMENTOS METODOLÓGICOS}

A partir dos procedimentos metodológicos, obtiveram-se mapas, gráficos e tabelas referentes às cidades de Rio Grande e São José do Norte, demonstrando seu crescimento econômico, populacional e espacial.

Os dados relativos ao crescimento populacional e renda per capta na pesquisa em questão foram obtidos nos censos do IBGE (Instituto Brasileiro de Geografia e Estatística) 1991 e 2010 bem como da FEE (Fundação de Economia e Estatística do estado do Rio Grande do Sul).

Com os dados obtidos foi possível identificar a posição do Produto Interno Bruto (PIB) de Rio Grande em relação a outros municípios do estado do Rio Grande do Sul; a evolução do PIB de Rio Grande e São José do Norte de 2000 a 2010; e PIB per capta dos municípios da Aglomeração Urbana do Sul (AUSUL). Eles possibilitaram também, quanto ao crescimento populacional, a identificação da evolução da população urbana de Rio Grande e São José do Norte de 1991 a 2010 bem como sua população estimada para 2018, década posterior.

Já o mapeamento da expansão urbana foi operacionalizado com técnicas de SIG. Em um Sistema de Informação Geográfica (SIG) o mundo real é estruturado segundo níveis de informação digitais (modelo numérico), ajustados a um sistema único de coordenadas, permitindo sua integração por meio de algoritmos lógicos, estatísticos e matemáticos. 0 processo pode ser comparado com o de sobreposição de mapas em material transparente, para visualização simultânea, como era realizado de forma pretérita. A vantagem do sistema digital é a facilidade de modificar os níveis de informação ou integrar vários deles, de maneira a produzir novas modelagens e simulações, isto é, produzir novas informações.

O sensoriamento remoto trata de medições à distância, ou seja, sem contato físico entre o alvo e o sensor, envolvendo o estudo da interação da radiação eletromagnética com os objetos terrestres (CROSTA, 1993; JENSEN, 1996).

O presente estudo foi realizado com imagens do sensor Thematic Mapper (TM), a bordo do satélite LANDSAT 5, correspondentes aos anos de 1990, 1996, 2001, 2006 e 2011; que foram conferidas com imagens de alta resolução disponíveis na mídia digital (Google Earth ${ }^{\odot}$ ). Como composição de referência para discriminar a área urbana foi a das bandas 345 em RGB, devido a maior variabilidade de tons, texturas e boa discriminação das outras coberturas do solo (SOUZA, 2012; HAMBURGER; VIEIRA, 2008).

As áreas urbanas digitalizaram-se como polígonos no programa SPRING (INPE), de maneira a evitar os erros associados ao uso de classificadores automáticos. Os polígonos de cada área urbana foram organizados por ano, conforme cores diferentes, para destacar a visualização do crescimento urbano, por meio do software ArcGis 9.3 (ESRI, 2014). Após a 
avaliação de áreas, os valores obtidos foram comparados com os dados dos censos disponíveis nos anos 1991, 2000 e 2010 (IBGE, 2014), sendo interpolados linearmente os valores para os anos de interesse resultando na coincidência de datas.

Quando a vetorização realizada foi confrontada com as imagens de alta resolução (Google Earth $\AA$ ), identificou-se confusão nas regiões com ocorrência acentuada de areia, devido à alta refletância de ambas as classes (areia e urbano).

Os períodos foram estabelecidos da seguinte maneira: para dados dos censos, o primeiro período corresponde ao intervalo entre 1991 e 2000 e o segundo período ao intervalo entre 2000 e 2010; para os resultados das manchas urbanas, o primeiro período equivale ao intervalo entre 1990 e 2001, e o segundo período ao intervalo entre 2001 e 2011.

Para concluir, no intuito de identificar os tipos de parcelamentos, da expansão periférica, se regulares ou irregulares, também foram realizadas entrevistas nas secretarias de coordenação e planejamento de ambas as cidades.

\section{O CRESCIMENTO DE RIO GRANDE E SÃO JOSÉ DO NORTE}

\section{Crescimento do PIB}

A partir da metade da década de 1990, com o processo de privatização operacional de atividades portuárias, o Porto do Rio Grande registrou incremento na movimentação de cargas. Esse foi um período de significativa relevância econômica com valores que refletiram positivamente na economia considerando as inúmeras atividades econômicas relacionadas ao setor portuário no município. É importante comentar também, fato que ocorreu na segunda metade da década 2000, o início da instalação de um polo de construção naval.

Nesse contexto, Domingues, Carvalho e Carvalho (2013) mostram a existência de uma forte correlação entre crescimento econômico mundial e o fluxo positivo de comércio internacional. Em outros termos, através do crescimento econômico mundial, as trocas comerciais entre diferentes regiões tendem também a aumentar. Dado que $80 \%$ dessas trocas ocorrem via oceanos e mares, as áreas portuárias do município de Rio Grande tendem a ter cada vez mais papel de destaque no contexto econômico mundial.

No período analisado (1990 - 2010), Rio Grande registrou crescimento significativo em elementos chave da economia configurando-se entre os municípios gaúchos com maior Produto Interno Bruto apresentando também evolução real das receitas fiscais locais.

Entre os municípios gaúchos, Rio Grande destacou-se positivamente em termos econômicos no período o que pode ser confrontado na tabela 1. Segundo dados de 2010, 
Rio Grande encontra-se em sexto lugar entre os municípios com maior PIB do Rio Grande do Sul.

Tabela 1 - Municípios com maior PIB - Rio Grande do Sul - 2010

\begin{tabular}{c|c}
\hline Cidade & PIB \\
\hline 1-Porto Alegre & 42.724 .991 .842 \\
2-Caxias do Sul & 16.471 .201 .247 \\
3-Canoas & 12.718 .014 .008 \\
4-Gravataí & 7.295 .812 .593 \\
5-Novo Hamburgo & 5.536 .879 .607 \\
6- Rio Grande & $\mathbf{5 . 1 4 3 . 1 2 0 . 7 1 8}$ \\
\hline
\end{tabular}

Fonte: FEE (2018).

Já na tabela 2 observa-se que o PIB per capta de Rio Grande encontra-se em sétimo lugar entre os 10 maiores do Rio Grande do Sul, suplantando Pelotas, outro município da zona sul do estado, com maior população, em mais do que o dobro. Outro dado interessante é quanto à evolução do PIB de Rio Grande, que apresentou um aumento de aproximadamente 129\% de 2005 a 2010 (figura 2). Este fato ocorreu principalmente em função de Rio Grande sediar a instalação do polo naval a partir de 2006.

Tabela 2 - 10 maiores PIBs per capta de municípios do RS - 2010

\begin{tabular}{c|c}
\hline Município & PIB per capta/2010 \\
& $\mathbf{R} \mathbf{2 0 1 0}$ \\
\hline 1 Triunfo & 219.695 \\
2 Canoas & 39.250 \\
3 Caxias do Sul & 37.823 \\
4 Santa Cruz do Sul & 35.304 \\
5 Porto Alegre & 30.303 \\
6 Gravataí & 28.526 \\
7 Rio Grande & $\mathbf{2 6 . 0 7 4}$ \\
8 Novo Hamburgo & 23.162 \\
9 Passo Fundo & 21.116 \\
10Pelotas & 12.899 \\
\hline
\end{tabular}

Fonte: FEE (2018).

Quanto ao PIB de São José do Norte, os dados indicam também sensível elevação de 2005 a 2010, no qual a cidade teve incremento da matriz econômica. São José do Norte, que possuía uma economia fundamentalmente primária, orientada pelas tradicionais atividades de cultivo de cebola e pesca, teve mais recentemente seu perfil modificado com o monocultivo de eucalipto e pinus e, após a introdução da indústria naval como uma das principais atividades da sua economia, já se apresentando como o segundo setor que mais contratou e o setor responsável por quase toda a criação de postos de trabalho, criando $91 \%$ dos novos empregos. O aumento do PIB de 2005 a 2010 correspondeu a 94\% (figura 3). 
Figura 2 - PIB do município de Rio Grande 2000/2005/2010

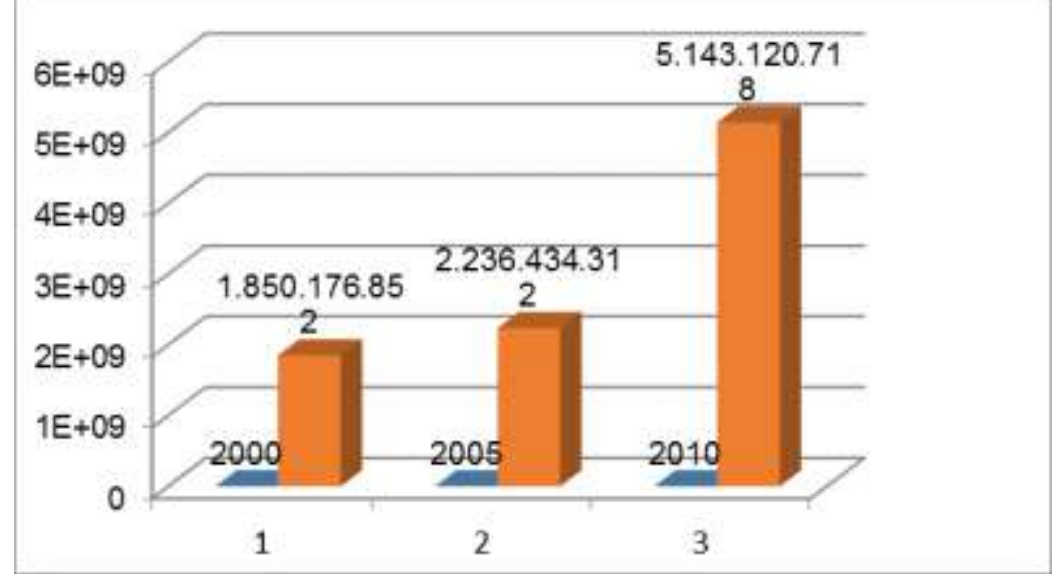

Fonte: FEE (2018).

Figura 3 - PIB do município de São Jose do Norte 2000/2005/2010

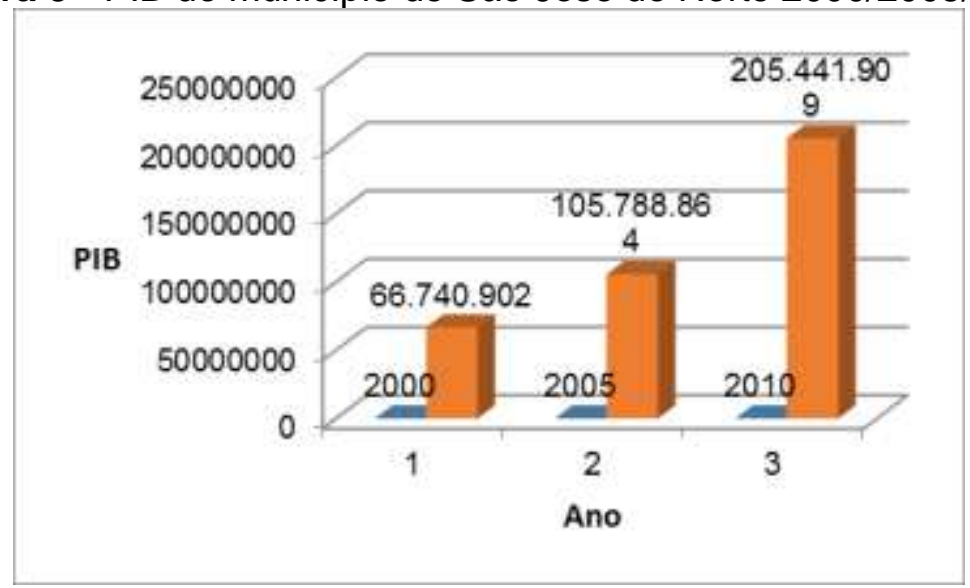

Fonte: FEE (2018).

Outro fato a ser observado é o destaque de Rio Grande ter em 2010 o maior PIB per capta em relação aos municípios da Aglomeração Urbana do Sul, Pelotas, São José do Norte e Capão do Leão e Arroio do Padre, inclusive suplantando o PIB do Rio Grande do Sul, enquanto São José do Norte apresenta o menor PIB da aglomeração (figura 4).

Rio Grande é a mais importante cidade portuária do estado sendo seu porto o único porto marítimo do Rio Grande do Sul. Esta característica torna-se base da economia do município. Nesse sentido, a soja, o trigo, o cavaco de madeira e os fertilizantes são os produtos mais movimentados.

É importante fazer referência a que a movimentação do porto cresceu à taxa média anual de $2,7 \%$ no período de 2003 - 2010 com um pico em 2010 ou 27.715.206 toneladas (tabela 3). Esses dados foram confrontados com o crescimento do PIB, no período, das cidades em questão.

Para concluir, tanto Rio Grande como São Jose do Norte apresentaram incremento do PIB principalmente no período 2005 a 2010 com atividades relacionadas ao polo naval. A 
primeira cidade com expressivo aumento no período, de 129\%, e a segunda, apesar de ser uma pequena cidade, de $94 \%$.

Figura 4 - PIB per capta de municípios da Aglomeração Urbana do Sul - 2010

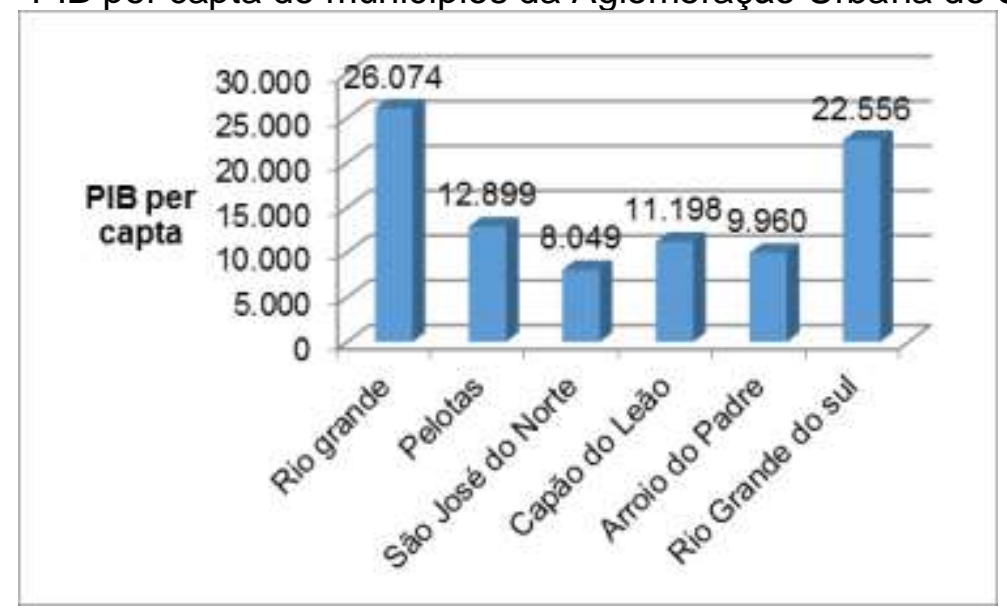

Fonte: FEE (2018).

Tabela 3 - Movimentação de cargas no porto do Rio Grande (2003-2010) (t)

\begin{tabular}{l|l|l|l|l}
\hline Ano & Carga geral & Granel Sólido & Granel líquido & Soma \\
\hline $\mathbf{2 0 0 3}$ & 5.710 .517 & 13.218 .239 & 4.357 .0 & $\mathbf{2 3 . 2 8 5 . 8 5 3}$ \\
$\mathbf{2 0 0 4}$ & 6.120 .508 & 12.339 .400 & 3.987 .924 & $\mathbf{2 2 . 4 4 7 . 8 3 2}$ \\
$\mathbf{2 0 0 5}$ & 6.408 .045 & 8.278 .146 & 3.333 .073 & $\mathbf{1 8 . 0 1 9 . 2 6 4}$ \\
$\mathbf{2 0 0 6}$ & 6.114 .533 & 12.462 .121 & 4.042 .869 & $\mathbf{2 2 . 6 1 9 . 5 2 3}$ \\
$\mathbf{2 0 0 7}$ & 6.539 .094 & 15.915 .997 & 4.427 .089 & $\mathbf{2 6 . 8 8 2 . 1 8 0}$ \\
$\mathbf{2 0 0 8}$ & 6.839 .442 & 13.880 .755 & 3.913 .045 & $\mathbf{2 4 . 6 3 3 . 2 4 2}$ \\
$\mathbf{2 0 0 9}$ & 6.980 .417 & 13.661 .873 & 3.266 .574 & $\mathbf{2 3 . 9 0 8 . 8 6 4}$ \\
$\mathbf{2 0 1 0}$ & 75.577 .191 & 16.463 .557 & 3.674 .458 & $\mathbf{2 7 . 7 1 5 . 2 0 6}$ \\
\hline
\end{tabular}

Fonte: Laboratório de Transportes e Logística (2013).

\section{Crescimento populacional}

Como afirmado anteriormente, o crescimento econômico de Rio Grande, através do Porto, tanto via aumento da movimentação de cargas como via indústria naval, gerou um importante efeito multiplicador na economia. Este movimento contribuiu diretamente no incremento da oferta de postos de trabalho e aumento de migração urbana (VACCOTTI, 2017).

Nesse contexto, os dados da evolução da população urbana de Rio Grande indicam um maior aumento de 1991 a 2000, 14.183 pessoas, ou 8,6\%, enquanto que de 2000 a 2010 compreendeu 10.221 pessoas ou 5,7\%. De 1991 a 2010 o aumento populacional foi de 24. 404 habitantes correspondendo a 14,2\% (figura 5 e tabela 4) o que pode ser explicado pela expectativa de aumento do emprego. 
Figura 5 - População urbana de Rio Grande 1991/2000/2010

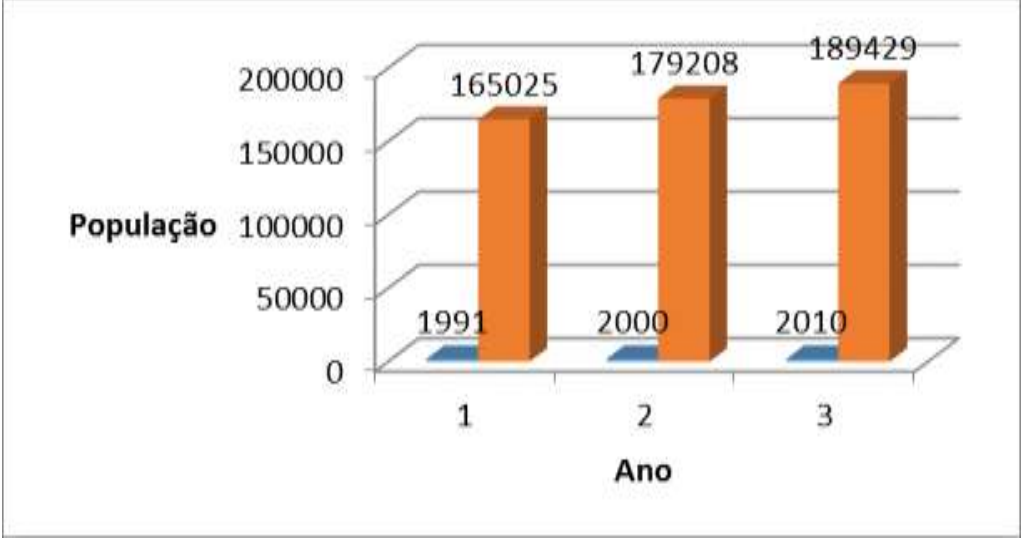

Fonte: IBGE (2014).

Tabela 4 - Aumento populacional e percentual 1991-2000/2000-2010 Rio Grande

\begin{tabular}{c|c|c}
\hline Serie & Aumento populacional & $\begin{array}{c}\% \text { Aumento } \\
\text { populacional }\end{array}$ \\
\hline $1991-2000$ & 14183 & $8,6 \%$ \\
$2000-2010$ & 10221 & $5,7 \%$ \\
\hline
\end{tabular}

Fonte: IBGE (2014).

Entre os anos de 2000 e 2010 o aumento do emprego formal no município foi de 12.244 trabalhadores, alta de 44,3\%. Esta alta esteve concentrada nos setores da indústria, comércio e serviços. Porém, em termos percentuais, a construção civil foi o setor que gerou o maior incremento no período (HOOD, 2011).

É importante salientar que Rio Grande foi marcado por crescimento populacional em outros períodos como, por exemplo, quando da implantação do frigorífico Swift em 1917/1918 (MARTINS, 2006). Outro período importante foi no período de 1975-1985 em que a implantação do superporto e do distrito industrial foi responsável por considerável fluxo migratório para a cidade (DOMINGUES, 1995).

Ramos e Martins (2017) informam que a população concentra-se predominantemente no pontal do município no centro; logo após há maior concentração nos bairros Cidade Nova, Cassino e Querência (este localizado ao sul do Cassino).

De acordo com Silva e Gonçalves (2014) o Polo Naval de Rio Grande atraiu, a partir de 2006, um grande número de trabalhadores de outras regiões do Brasil. Esse fluxo migratório ocasionou um aumento na demanda por imóveis que associado à baixa oferta disponível causou um impacto nos preços, tanto para locação como para venda. O autor comenta que de 2000 a 2006 o preço dos imóveis aumentaram, em média, 70\%, enquanto que, a partir da implantação do polo naval - 2006 a 2012, o incremento foi superior a 330\%.

Uma das transformações profundas na área de influência do polo naval da cidade do Rio Grande é a que diz respeito ao aumento populacional. O fluxo migratório ocasionou um 
aumento na demanda por imóveis que associado à baixa oferta disponível causou um impacto nos preços, tanto para locação como para venda (SILVA; GONÇALVES, 2014).

Com um déficit de 17 mil moradias que aumenta com a chegada de gente de outros estados, a construção civil foi o setor mais aquecido da economia de Rio Grande no período.

E possível identificar que embora extremamente concentrada nas grandes metrópoles, a população urbana brasileira passa no período por processo de reversão de sua polarização. Os dados obtidos revelam esse dinamismo em Rio Grande, e entre os fatores que imprimiram incremento ao seu desempenho demográfico podem-se elencar os fatores endógenos ao próprio dinamismo econômico local, as mudanças recentes nos padrões locacionais da indústria (polo naval) e as transformações mais visíveis no movimento migratório regional. As cidades intermediárias (entre 50 mil e 500 mil habitantes), que em 1970 detinham 19,1\% da população urbana nacional, passaram em 1991 a agrupar quase 1/3 desta mesma população (ANDRADE; SERRA, 1998; AMORIM FILHO; SERRA, 2001). Assim, o maior aumento populacional das cidades entre 1991 e 2000 pode ser explicado pelo crescimento das cidades intermediárias no período bem como a atração da atividade portuária.

No que se refere a São José do Norte identificou-se um aumento populacional de $28 \%$ de 1991 a 2000 e 0,5\% de 2000 a 2010 (figura 6 e tabela 5). No período de 1991 a 2010 o valor foi de 3.873 pessoas ou $28,6 \%$. Os dados indicam que em ambas as cidades 0 aumento da população urbana foi maior no período de 1991 a 2000.

Figura 6 - População urbana de São José do Norte 1991/2000/2010

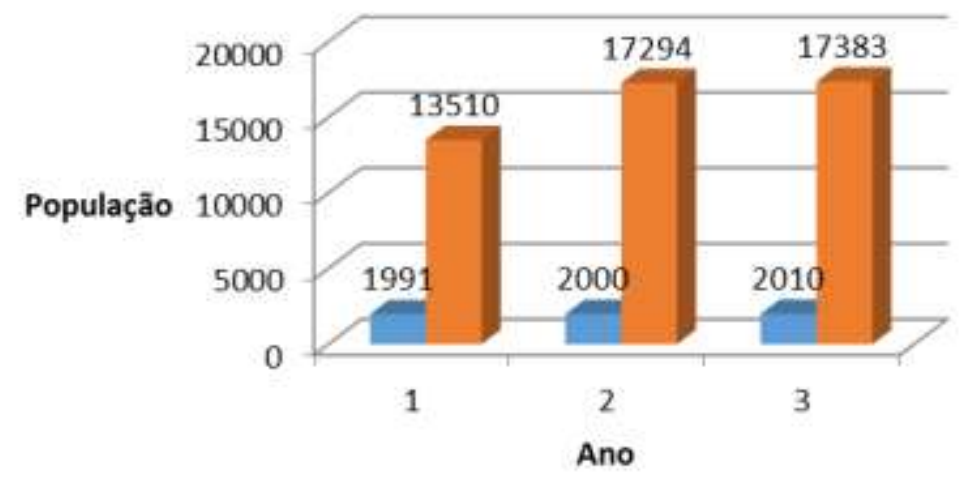

Fonte: IBGE (2014).

Tabela 5 - Aumento populacional e percentual 1991-2000/2000-2010 - São José do Norte

\begin{tabular}{c|c|c}
\hline Serie & $\begin{array}{c}\text { Aumento } \\
\text { populacional }\end{array}$ & $\begin{array}{c}\% \text { Aumento } \\
\text { populacional }\end{array}$ \\
\hline $1991-2000$ & 3784 & $28 \%$ \\
$2000-2010$ & 89 & $0,5 \%$ \\
\hline
\end{tabular}

Fonte: IBGE (2014). 
Quanto à migração, para as cidades em questão identificou-se que em 2005 houve 12.669 migrantes em Rio Grande e 768 em São José do Norte. Esses dados correspondem a pessoas de cinco anos ou mais de idade que não residiam nas zonas urbanas das cidades no período (IBGE, 2010). Acerca da dinâmica das cidades pequenas próximas aos grandes centros, como é o caso de São José do Norte, pode-se fazer referência a Endlich (2006, p. 189) que registrou:

As pequenas cidades próximas a áreas metropolitanas ou aglomerados urbanos mantêm ou ampliam os volumes demográficos, mas amiúde perdem a autonomia e funcionam como extensões daquelas áreas. Assim, além das pequenas cidades funcionarem como locais de moradia dos trabalhadores que atendem tanto a agricultura moderna como as agroindústrias, elas também abrigam trabalhadores cujos postos de trabalho estão localizados em cidades maiores.

Para concluir segue na tabela 6 a projeção da população urbana de Rio Grande e São Jose do Norte para 2018. Nesse sentido estima-se considerando a taxa de urbanização de 2010 (91\% para Rio Grande e 68\% para São José do Norte), Rio Grande terá um aumento populacional de 12.175 habitantes, 6,4\%, enquanto São José do Norte 1.255 habitantes, num aumento populacional de $7,2 \%$. Assim considerando os aumentos percentuais populacionais explicitados identifica-se que na década de 1990 a 2000 houve o maior aumento tanto em Rio Grande como São José do Norte, 8,6\% em Rio Grande e 28\% em São José do Norte.

Tabela 6 - Projeção da população urbana Rio Grande e São José do Norte (2018)

\begin{tabular}{c|c|c|c|c|c}
\hline Local & $\begin{array}{c}\text { População } \\
\text { Municipal } \\
\text { estimada } \\
\mathbf{2 0 1 8} \text { (hab) }\end{array}$ & $\begin{array}{c}\text { População } \\
\text { urbana 2010 } \\
\text { (hab) }\end{array}$ & $\begin{array}{c}\text { População } \\
\text { urbana } \\
\text { estimada } \\
\mathbf{2 0 1 8} \text { (hab) }\end{array}$ & $\begin{array}{c}\text { Aumento } \\
\text { população } \\
\text { estimada } \\
\mathbf{2 0 1 8} \text { (hab) }\end{array}$ & $\begin{array}{c}\text { Projeção } \\
\text { percentual } \\
\text { de aumento } \\
\text { populacional } \\
\text { (hab) }\end{array}$ \\
\hline $\begin{array}{c}\text { Rio Grande } \\
\text { São José do } \\
\text { Norte }\end{array}$ & 210.005 & 189.429 & 201.604 & 12.175 & $6,4 \%$ \\
\hline
\end{tabular}

Fonte: IBGE (2018).

Nesse contexto, o porto da cidade de Rio Grande ocasionou transformações profundas no que diz respeito ao aumento populacional, pois a consolidação de tal empreendimento transformou tanto Rio Grande quanto São José do Norte a partir da atração de migrantes. A maior parte dos novos moradores é proveniente das pouco mais de cem cidades da metade sul do estado e inclusive de outros estados do país (IBGE, 2018). 


\section{Expansão urbana}

No que se refere à expansão da área urbanizada, Rio Grande apresenta grande parte de áreas desfavorecidas (SOUZA; MARTINS, 2016). Estima-se que moravam, no ano de 2000, 32.313 pessoas em assentamentos precários, correspondendo a $18,12 \%$ da população, proporção bastante alta (MARQUES, 2007).

Essa área passa de 23,57 quilômetros quadrados em 1990 para 51,49 quilômetros quadrados em 2011, num total de 27,92 quilômetros quadrados ou $118,45 \%$. A expansão pós 1990 acontece a sudoeste na península que avança na Lagoa dos Patos, na zona portuária, polo naval localizado às margens do canal de ligação da Lagoa dos Patos com o oceano, no balneário Cassino, núcleo isolado localizado a sul às margens do Oceano Atlântico que apresenta crescimento contínuo das suas bordas e na Quinta, povoação localizada a oeste do centro urbano (figura 7).

Figura 7 - Mapa resultante da vetorização do município de Rio Grande, sobreposta a uma imagem do sensor TM pertencente ao satélite LANDSAT

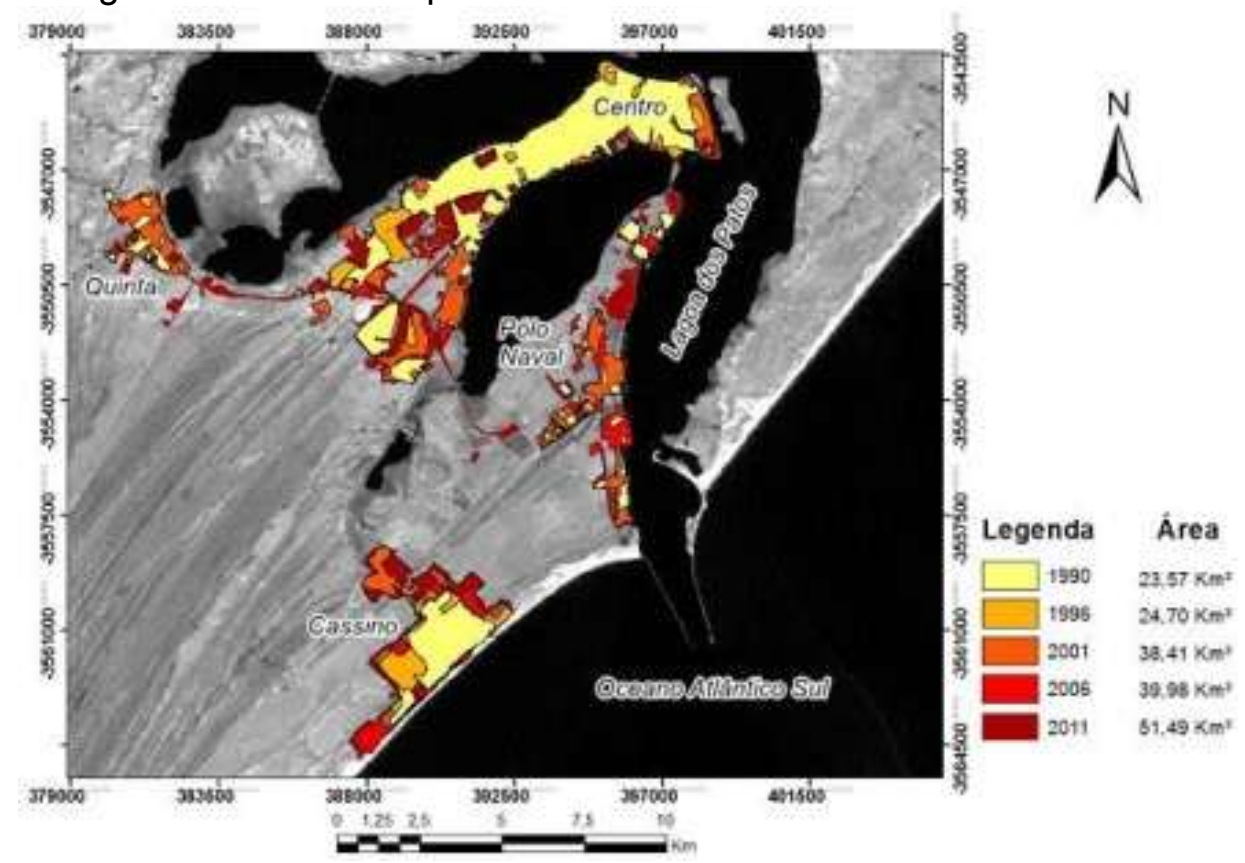

Fonte: autores (2018).

E importante destacar que o Cassino, embora seja o principal balneário do Sul do Rio Grande do Sul, para onde no verão aflui a população de muitos de seus municípios, tornouse residência de grande parte da classe média alta local, estudantes e funcionários da Universidade Federal do Rio Grande (ver núcleo central em amarelo no mapa - figura 7), e apresenta também população de classe de baixo poder aquisitivo em sua periferia; nas bordas paralelas ao Oceano Atlântico. Nesse sentido, a partir de 1996 observa-se a expansão periférica principalmente por parcelamentos irregulares, segundo dados de 
entrevistas na prefeitura municipal em 2018, Já na Quinta, segundo esses dados, identificase efetiva expansão a partir de 2001 também por parcelamentos irregulares.

Observa-se também que a expansão de Rio Grande se faz a partir de quatro polos de crescimento. O inicial, no centro, na ponta da península agora seguindo de modo fragmentado em direção a Pelotas e Cassino a sudoeste; na Quinta, Cassino e Polo Naval (figura 7).

Por fim, nesse processo de expansão observam-se os dois fenômenos anteriormente citados, os quais podem ser visualizados na figura 7, a produção de vazios urbanos e 0 crescimento a partir dos eixos de transporte tanto intra, como inter urbano (VILLAÇA,2001).

No caso de São José do Norte, quanto à expansão a área urbana apresenta 0,7335 quilômetros quadrados em 1990 e 2,7765 quilômetros quadrados em 2011, num total de 2,043 quilômetros quadrados ou 278,52\% (figura 8). A expansão urbana neste caso é contínua a partir do núcleo principal. Pode-se constatar também, com dados de entrevistas na prefeitura municipal, que $70 \%$ dos loteamentos da cidade são irregulares ou invasões, muitas delas em APPs, Áreas de Preservação Permanente, nesse caso específico dunas, cuja população vem tanto do interior do município, quanto de outras localidades a fim de trabalhar na indústria naval ou em empresas agropecuárias no interior. Assim, mais uma vez é constatada a procura por terra periférica com menor valor agregado, principalmente pela população com menor poder aquisitivo.

Figura 8 - Mapa resultante da vetorização do município de São José do Norte, sobreposta a uma imagem do sensor TM pertencente ao satélite LANDSAT 5

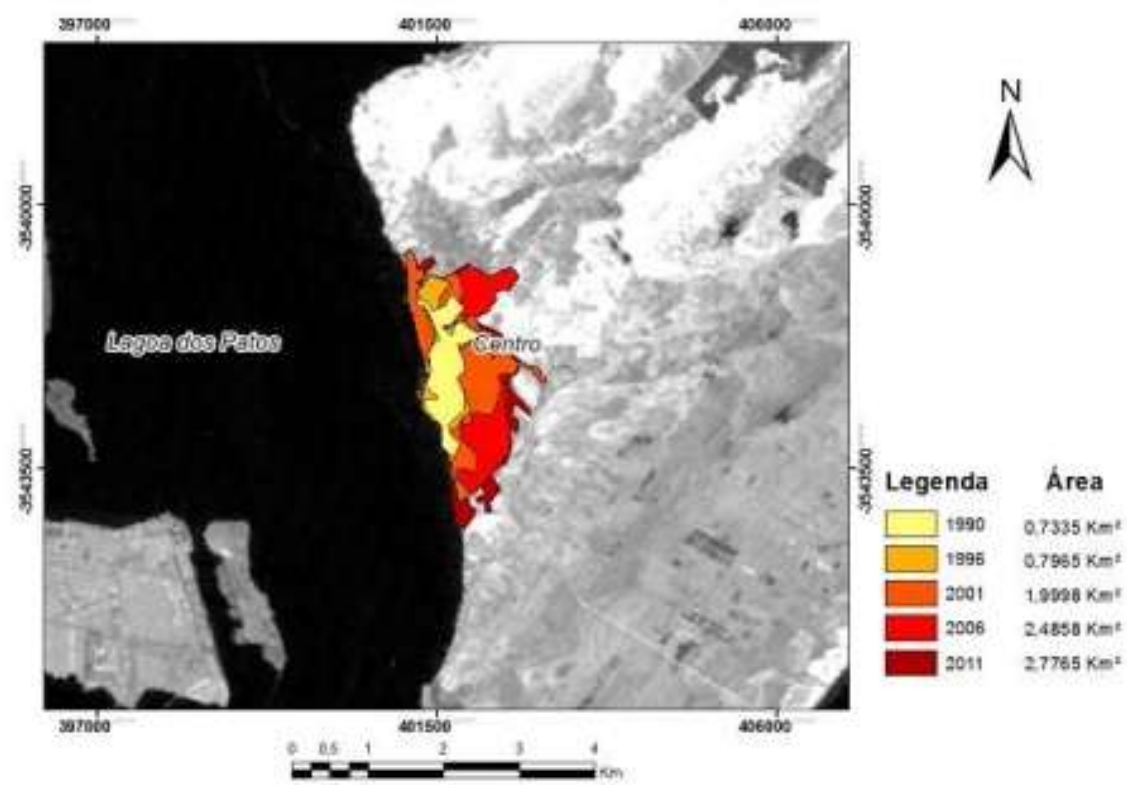

Fonte: autores (2018).

De acordo com Marques, Siedenberg e Santos (2009) houve, no período, violento êxodo rural para a sede do município (principalmente na periferia), fato esse proporcionado 
Atividade Portuária, Globalização e Crescimento de Rio Grande e São José do Norte - RS - Brasil...

pela falta de energia elétrica, telefone, e serviços de saúde e educação. Além disso, a deficiência de acessibilidade, com estradas em péssimo estado, dificulta além da locomoção o escoamento da produção. A ocupação do solo ocorreu de forma desordenada e irregular. Atualmente, a zona urbana do município se caracteriza pela ocupação de áreas de preservação, áreas de risco, em terrenos de marinha e áreas pertencentes ao Patrimônio da União. A maioria dos imóveis são posses em loteamentos e ocupações irregulares, sem nenhum título de propriedade, em ruas abertas à própria sorte e sem infraestrutura básica. Cabe salientar que São José do Norte tem com Rio Grande uma relação de dependência econômica, fato esse observado na sua configuração socioespacial ou nos seus bairros dormitórios. A perspectiva da construção de um terminal da Aracruz Celulose no município criou uma expectativa na população.

\section{Economia urbana e o crescimento de Rio Grande e São José do Norte}

A cidade é um sistema formado por diversas partes combinando uma dinâmica de cooperação e conflito. O espaço urbano está intrinsecamente relacionado com o movimento da sociedade na qual a economia urbana consiste em elemento chave.

A partir dos anos 1990, com a intensificação do processo de globalização, caracterizado pela crescente integração das esferas da produção, do consumo e da circulação em todas as escalas geográficas, novas demandas foram colocadas sobre os portos e cidades portuárias (MONIÉ; VASCONCELOS, 2012).

Observa-se que a partir da implantação da atividade portuária as cidades estudadas tornaram-se mais capazes de abrigar uma extensa gama de atividades revelando uma maior complexidade na economia urbana no período.

Sobre o elencado acima se pode fazer referência a Santos (2008) quando comenta que o processo de urbanização tem um papel relevante no mercado que cresce e adquire espessura e segmentação.

Nas décadas de 1990 e 2010 as modernizações do território de Rio Grande e São José do Norte foram acompanhadas por um intenso processo de urbanização - aumento populacional, do PIB e da expansão urbana. Para compreender essa dinâmica há de se levar em conta os circuitos da economia urbana (SANTOS, 2008); circuito superior e circuito inferior.

No caso abordado, no circuito superior a atividade portuária seria o elemento principal. Complementar a esse se tem o circuito marginal superior constituído de formas mistas, como a indústria da construção civil. Já no circuito inferior (resultado indireto dessa modernização) observa-se a integração de formas de fabricação, comercio e serviços sem uso intensivo de capital, ou comercio e serviços com baixo grau de tecnologia e organização 
que satisfazem a demanda dos estratos inferiores com um baixo grau de capital. É importante ressaltar que existe uma relação dialética entre os dois circuitos. Ambos são opostos e complementares embora o circuito inferior seja dominado pelo superior.

Assim, a atividade portuária local criou uma demanda por trabalho e uma cadeia produtiva, mas também uma expectativa, ambas relacionadas no caso com o crescimento populacional, aumento do PIB e expansão do espaço urbano. Observa-se, dessa forma, a mobilidade de população para todos os circuitos a partir da imigração e mesmo o aproveitamento de força de trabalho local.

Concluindo, a atividade portuária corresponde à atividade principal do circuito superior e é macro organizadora do espaço local, enquanto as outras atividades, tanto do circuito intermediário como inferior, dependem basicamente dela. A própria organização do espaço é função da estrutura da produção.

\section{CONSIDERAÇÕES FINAIS}

A partir da pesquisa observa-se, no período de 1990 a 2010, o crescimento econômico, populacional e espacial, tanto de Rio Grande quanto de São José do Norte, com o crescimento dessa última dependente da primeira. Nesses termos, São Jose do Norte consiste em um subúrbio-dormitório, e também reservatório de força de trabalho. Seu crescimento econômico, populacional e sua expansão periférica é explicado pelo fato de a terra urbana lá ter menor preço ou ser mesmo obtida em processos de invasão. São Jose do Norte funciona como periferia de Rio Grande.

Rio Grande, como São Jose do Norte, apresentaram incremento do PIB principalmente no período de 2005 a 2010 com atividades relacionadas ao polo naval, a primeira com expressivo aumento no período, de 129\%, e a segunda, apesar de ser uma pequena cidade, de $94 \%$.

Quanto ao crescimento demográfico, de 1991 a 2010 Rio Grande apresentou um aumento de 24.404 habitantes ou $14,2 \%$ do total, enquanto São José do Norte 3873 habitantes, ou $28,6 \%$ do total.

No referente à expansão, a cidade de Rio Grande apresentou 27,9 quilômetros quadrados de expansão absoluta e $116,7 \%$ de expansão relativa, já a cidade de São José do Norte 2,04 quilômetros quadrados de expansão absoluta e $278,5 \%$ de expansão relativa, podendo-se inferir, com esses dados, que a cidade satélite cresceu mais proporcionalmente.

Cabe salientar que, sobretudo Rio Grande constitui, cada vez mais, uma ponte entre o global e o local, em vista das necessidades de intermediação e da demanda também crescente de relações, e ainda ressaltar que a partir da década de 1990, e principalmente depois de 2000 , os tradicionais movimentos migratórios do tipo cidade-cidade foram 
Atividade Portuária, Globalização e Crescimento de Rio Grande e São José do Norte - RS - Brasil...

observados em Rio Grande, e já em São José do Norte principalmente o movimento campocidade.

Assim, mostra-se premente o papel do Estado no crescimento do sistema (CANO, 2008; PIMENTA, 2014). A instalação da indústria naval em Rio Grande gerou grandes mudanças na matriz produtiva da região (CARVALHO; DOMINGUES, 2010).

Em conclusão pode-se admitir que as relações entre cada um dos dois sistemas de fluxo da economia urbana de um lado, e a macro organização do espaço de outro, são condicionadas pelas condições históricas gerais sob as quais modernas atividades têm penetrado nas cidades.

\section{REFERÊNCIAS}

ANDRADE, T. A.; SERRA, R. V. O recente desempenho das cidades médias no crescimento populacional urbano brasileiro. Rio de Janeiro: IPEA, 1998. (Texto para discussão, n. 554).

AMORIM FILHO, O.; SERRA, R. V. Evolução e perspectivas do papel das cidades médias no planejamento urbano e regional. In: ANDRADE, T. A.; SERRA, R. V. (org.). Cidades médias brasileiras. Rio de Janeiro: IPEA, 2001. p. 1-34.

CANO, W. Desconcentração produtiva regional do Brasil 1970-2005. São Paulo: UNESP, 2008.

CARVALHO, D. S.; DOMINGUES, M. V. R. O polo naval de Rio Grande e os desafios urbanos para o desenvolvimento regional: uma nova centralidade econômica emerge no Rio Grande do Sul. Pelotas: UFPEL, 2010.

CORRÊA, R. L. As pequenas cidades na confluência do urbano e do rural. GEOUSP Espaço e Tempo, São Paulo, n. 30, p. 05-12, 2011.

CORRÊA, R. L. Globalização e reestruturação da rede urbana - uma nota sobre as pequenas cidades. Território, Rio de Janeiro, v. 4, n. 6, p. 43-53, jan./jun. 1999.

CROSTA, A. P. Processamento digital de imagens de sensoriamento remoto. Campinas: UNICAMP, 1993. 170 p.

DOMINGUES, M. V. R. Desenvolvimento e consolidação do polo naval e offshore de Rio Grande. Rio Grande: FURG, 2009.

DOMINGUES, M. V. R.; CARVALHO, D. F.; CARVALHO, A. B. O polo naval offshore e o desenvolvimento regional da metade sul do Rio Grande do Sul. Ensaios FEE, Porto Alegre, v. 34, n. esp., p. 933-954, 2013.

DOMINGUES, M. V. R. Superporto de Rio Grande: plano e realidade. Elementos para uma discussão. 1995. Dissertação (Mestrado em Geografia) - Universidade Federal do Rio de Janeiro, Rio de Janeiro, 1995.

ENDLICH, A. M. Pensando os papéis e significados das pequenas cidades no Noroeste do Paraná. 2006. Tese (Doutorado em Geografia) - Faculdade de Ciências e Tecnologia - Universidade Estadual Paulista, Presidente Prudente. 2006.

ESRI. The Arc GIS Plataform. 2014. Disponível em: https://www.esri.com/esrinews/arcnews/summer14articles/the-arcgis-platform-in-2014. Acesso em: 29 jun. 2018. 
FEE - FUNDAÇÃO DE ECONOMIA E ESTATÍSTICA. Estimativas populacionais.

Disponível em: http://www.fee.rs.gov.br/indicadores/populacao/estimativas-populacionais/. Acesso em: 10 set. 2018.

FEIJÓ, F. T.; MADONO, D. T. Polo Naval do Rio Grande: potencialidades, fragilidades e a questão da migração. In: ENCONTRO DE ECONOMIA GAUCHA, 6., 2013, Porto Alegre. Anais [...]. Porto Alegre: UFRGS, 2013. p.123-136.

GUSMÃO, P. Apropriação e ordenamento territorial na zona costeira no estado do Rio de Janeiro. Revista Brasileira de Estudos Urbanos e Regionais, São Paulo, v. 12, n. 2, p. 23-37, 2010.

HAMBURGER, D. S.; VIERA, I. M. Estudo do comportamento espectral de alvos urbanos para discriminação de áreas residenciais. São José dos Campos: Instituto Nacional de Pesquisas Espaciais - INPE, [2008]. Disponível em:

http://marte.sid.inpe.br/col/dpi.inpe.br/marte@80/2008/08.18.13.54/doc/383-390.pdf. Acesso em: 28 jun. 2018.

HOOD, A. S. S. Comportamento do emprego formal no município do Rio Grande 20002010. 2011. Dissertação (Mestrado em Economia) - Pontifícia Universidade Católica do Rio Grande do Sul - PUCRS, Porto Alegre, 2011.

IBGE. Censos demográficos, 2014. Disponível em:

https://ww2.ibge.gov.br/home/estatistica/populacao/censodem/default_censo1991.shtm. Acesso em: 29 jun. 2018.

IBGE. Estimativas de população, 2018. Disponível em: https://www.ibge.gov.br/estatisticas-novoportal/sociais/populacao/9103-estimativas-depopulacao.html?=\&t=resultados2018. Acesso em: $21 \mathrm{fev} .2019$.

JENSEN, J. R. Introductory digital image processing: a remote sensing perspective. Upper Saddle River: Prentice Hall, 1996.

MARQUES, E. Assentamentos precários no Brasil urbano. Brasília: Ministério das Cidades; São Paulo: Centro de Estudos da Metrópole, 2007. Disponível em: http//wwwcentrodametrópole.org.br/mc. Acesso em: 18 set. 2018.

MARQUES, C. B.; SIEDENBERG, D. R.; SANTOS, C. H. S. O processo de urbanização e as nuances do desenvolvimento local - São José do Norte, RS - Brasil. In: CONGRESSO DE DESENVOLVIMENTO REGIONAL DE CABO VERDE, 1., CONGRESSO da APDR, 15. Cabo Verde. Anais [...] Cabo Verde, 2009. p. 87-96

MARTINS, C. A. Á. Morar e habitar em áreas portuárias na cidade do Rio Grande, RS.

Scripta Nova: Revista Electrónica de Geografia y Ciencias Sociales, Barcelona, v. 14, n. 331, p.1-16, ago. 2010.

MARTINS, S. F. Cidade do Rio Grande: industrialização e urbanidade. Rio Grande: FURG, 2006.

MONIÉ, F. Globalização, modernização do sistema portuário e relações cidade/porto no Brasil. In: SILVEIRA, M. R. (org.): Geografia dos transportes, circulação e logística no Brasil. São Paulo: Outras Expressões, 2011. p.299-330.

MONIÉ, F.; VASCONCELOS, F. N. Evolução das relações entre cidades e portos: entre lógicas homogeneizantes e dinâmicas de diferenciação. Revista Franco Brasileira de Geografia, Paris, n.15, p. 24-43, 2012.

OLIVEIRA, A. L. C. O portal meridional do Brasil Rio Grande, São José do Norte e Pelotas no período colonial 1737 a 1822. 2012. Tese (Programa de Pós-graduação em Planejamento Urbano e Regional) - Universidade Federal do Rio Grande do Sul, Porto Alegre, 2012. 
PIMENTA, C. A. M. Tendências do desenvolvimento: elementos para reflexão das dimensões sociais na contemporaneidade. Revista Brasileira de Gestão e

Desenvolvimento Regional, Taubaté, SP, v. 10, n. 3, n. esp., p. 44-66, set. 2014.

LABORATÓRIO DE TRANSPORTES E LOGÍSTICA - LABTRANS. Plano mestre: Porto do Rio Grande. Florianópolis, 2013. Disponível em http://infraestrutura.gov.br/images/ SNP/planejamento_portuario/planos_mestres/sumario_executivo/se26.pdf. Acesso em: 25 jan. 2019.

RAMOS, B. R.; MARTINS, S. F. Polo naval e a produção habitacional em Rio Grande. Boletim de Geografia, Maringá, v. 35, n.3, p. 56-73, 2017.

SALVATORI, E. et al. Crescimento horizontal da cidade de Rio Grande. Revista Brasileira de Geografia, Rio de Janeiro, v. 51, n. 1, p. 27-72, jan./mar. 1989.

SANTOS, M. O espaço dividido: os dois circuitos da economia urbana dos países subdesenvolvidos. São Paulo: EDUSP, 2008.

SILVA, R. P., GONÇALVES, R. R. O Polo Naval e os preços dos imóveis na cidade do Rio Grande-RS. In: ENCONTRO DE ECONOMIA GAÚCHA. Fundação de Economia e Estatística (FEE), 7., 2014, Porto Alegre. Anais [...]. Disponível em:

http://www.fee.rs.gov.br/wp-content/uploads/2014/05/201405267eeg-mesa23-polonav alprecosimoveis.pdf. Acesso em: 22 set. 2018.

SOUZA, I. M. Sensoriamento remoto orbital aplicado a estudos urbanos. São José dos Campos: Instituto Nacional de Pesquisas Espaciais - INPE, 2012.

SOUZA, P. R. S.; MARTINS, C. A. A. Áreas urbanas desfavorecidas do município do Rio Grande-RS, Geosul, Florianópolis, v. 31, n. 62, p. 221-246, jul./ago. 2016.

SOUZA, S. E. D. Os impactos do polo naval de Rio Grande sobre emprego por escolaridade no COREDE SUL. In: ENCONTRO DE ECONOMIA GAÚCHA - FEE, 7., 2014, Porto Alegre: FEE, 2014. p.156-165.

VACCOTTI, L. Migraciones e informalidad urbana. Dinámicas contemporâneas de la exclusión y inclusión em Buenos Aires. EURE, Santiago Del Chile, v.43, n. 129, p.49-70, mayo 2017.

VILLAÇA, F. O espaço intra-urbano no Brasil. São Paulo: Estúdio Nobel, 2001.

WEIMER, G. Origens e evolução das cidades Rio-Grandenses. Porto Alegre: Livraria do Arquiteto, 2004.

Recebido: outubro de 2018. Aceito: março de 2019. 